\title{
Un análisis del cuerpo trans en el cortometraje "Loxoro"
}

- Sophia Gomez

\section{Resumen}

"Loxoro" es un cortometraje estrenado en el año 2012 y dirigido por la cineasta peruana Claudia Llosa. La historia muestra la búsqueda de Makuti, una mujer trans que trata de encontrar a Mía, su hija, también trans, quien ha desaparecido hace algunos días. Esta reseña se enfoca en una representación emergente en dicho film: el cuerpo trans. A partir del análisis de algunas escenas claves del cortometraje, se argumenta que el cuerpo trans sufre una serie de violencias, cuyo destino final es la muerte o erradicación del mismo, debido a que su existencia o posibilidad de existencia cuestiona el orden heteronormativo que representa a los agresores. En otras palabras, la existencia de Mía desestabiliza las raíces de la identidad de los agresores: la heteronormatividad violenta.

\section{Palabras clave}

Mujer trans, performatividad, cuerpo, violencia. 


\title{
The body of the trans woman: an analysis of the short film "Loxoro"
}

- Sophia Gomez

\begin{abstract}
"Loxoro" is a short film released in 2012 and directed by the Peruvian filmmaker Claudia Llosa. The story shows the search of Makuti (a trans woman), who tries to find her daughter Mia, who has disappeared a few days ago. This review focuses on an emerging representation on the film: the trans body. Through the analysis of key scenes, it is argued that the trans body experiences a deep and cruel violence, whose final objective is the death or eradication of the body itself, because its existence or possibility of existence questions the heteronormative order that represents the aggressors. In other words, the existence of Mía destabilizes the origins of the identity of the aggressors: the violent heteronormativity.
\end{abstract}

\section{Keywords}

Trans woman, performativity, body, violence. 
El film se inicia con la figura de Mía como única protagonista. Ella, una chica trans y trabajadora sexual, aparece en la primera escena del corto frente a la cámara, sola, haciendo movimientos sinuosos. De fondo, se observa estampas religiosas de la virgen María. La cámara enfoca y desenfoca, alternativamente, ambas figuras: al inicio es Mía la figura y las estampitas el fondo, luego esto cambia. La siguiente escena muestra un escenario distinto. Mía está sola, de espaldas a la cámara, en un lugar oscuro y descampado. A su izquierda está una carretera, a su derecha un barrio con casas de material precario. Ella camina en el terral en medio de ambos espacios, lejos de la comunidad: no por la distancia concreta sino por su posición en la sociedad, en ese espacio intermedio ella es invisible. Su caminata se interrumpe por la aparición de un carro con tres ocupantes. Mía intenta salir de la vista de estos sujetos, pero ellos no lo permiten. Se acercan preguntando cuánto cobra. Les interesa su cuerpo sí, pero no como fuente de placer sino para cuestionarlo y destruirlo. Los tres sujetos se aproximan a ella en son burlón e inician una serie de prácticas - focalizadas en el cuerpo de ésta - destinadas a desmantelar la performatividad de Mía; es decir, atacar y cuestionar las prácticas corporales, actitudes, posturas y movimientos que se identifican como "propios" de la lógica binaria hombre-mujer y que, a través de esta repetición cotidiana y continua, brindan la ilusión de ser naturales (Butler, 2001).

La primera acción es un ataque a la construcción corporal de Mía como mujer trans: "remueven" la tela con la que Mía da forma a sus pechos. Al despojarla de este seno, los hombres intentan develar la supuesta artificialidad del cuerpo trans. Esta acción está acompañada de risas e insultos, formas simbólicas de reafirmar la falsedad de su cuerpo, de transmitirle una verdad que ella negaría - a ojos de estos hombres con su performatividad. Así, los insultos serían una operación de injuria que busca reposicionar a Mía en una identidad "natural" a través de señalar la anormalidad o rareza de su cuerpo y mostrarla como un ser equivocado, desautorizado en su subjetividad (Eribon, 2001). A su vez, este movimiento (remover la tela que da forma a los senos), será la primera práctica de una serie de intentos pedagógicos y "correctivos" (Butler, 2004; Foucault, 2011), con el objetivo de enseñarle su supuesta verdadera identidad (lo masculino) y castigarla por tratar de contravenir esta supuesta naturalidad identitaria.

La escena pasa rápidamente a otra acción. Los tres sujetos se acercan más a Mía y uno de ellos se coloca encima de ella. El momento sugiere que Mía está siendo ultrajada sexualmente, pero las imágenes se tornan borrosas y los sonidos que acompañan el momento disminuyen. Estas técnicas visuales narrativas producen un efecto particular: distancia, al espectador, de la crudeza de la violencia sexual. $\mathrm{O}$, mejor dicho, la distorsión sensorial sería una forma de pensar en lo real de la violencia sexual.

La historia cambia a una secuencia que puede ser más claramente codificada. El rostro de Mía es enfocado directamente, está llorando. Los hombres continúan aplicando técnicas de cuestionamiento de su performatividad y rituales de normalización o corrección (Butler, 2004; Foucault, 2011): le cortan el pelo (los agresores murmuran que "ya se está haciendo hombre") y la obligan a hacer "ranas" (saltos). Pareciera que allí terminará todo. Pero hay uno, el que la agrede sexualmente, quien lleva el ritual al siguiente nivel: mientras Mía salta, grita "(hazlo) como hombre” acercándose 
rápidamente a ella. La escena termina en un corte abrupto, siendo la última vez que los espectadores la vemos con vida. Nuevamente, observamos cómo la retirada abrupta de la imagen simbolizaría la ocurrencia de algo irrepresentable: la muerte de la protagonista después de que su cuerpo ha sufrido el cuestionamiento físico (a través de las prácticas normalizadoras sobre éste) de su propia construcción genérica. Resulta importante notar cuál ha sido la secuencia en la escalada de violencia hacia Mía: no bastó con infligir a su cuerpo unas prácticas sádicas de normalización a través de la violencia, sino que una vez que "extrajeron" o "hicieron emerger" al "hombre" en ella, muere.

Así, el cuerpo trans dentro del fragmento analizado es un cuerpo ficticio, que deberá ser corregido o redirigido a través de prácticas o rituales de normalización violentas, ya que cuestionan el orden establecido (la heteronormatividad) y las identidades que se han construido en torno a este. Por esta razón, podríamos hipotetizar que el control y ensañamiento contra los signos de "feminidad" del cuerpo trans es una forma que tienen los agresores de reafirmar y no dudar de su propia construcción identitaria. Observamos que, desde esta perspectiva, la construcción identitaria de la heteronormatividad necesitaría al Otro (la identidad trans: ejemplificadas a través de una construcción corporal y un lenguaje disidente) para su definición y construcción (Hall, Restrepo, Walsh \& Vich; 2010). En este caso particular, podríamos plantear que, para los agresores de Mía, es la destrucción del Otro - que llega a su cumbre a través del asesinato y desaparición de la protagonista, pero que se inicia con las prácticas violentas y normalizadoras sobre su cuerpo - lo que permitiría salvaguardar y validar sus propias identidades, desde una masculinidad heteronormada y violenta.

Otro aspecto que esta representación informa es que el cuestionamiento del orden heteronormativo (realizado por la existencia de la mujer trans) debe ser castigado con la máxima pena (la muerte) pero pasando antes por un proceso de humillación y tortura hacia aquella persona que ha infligido el supuesto "orden natural”. Además, estos ejercicios de control no ocurren en un ámbito privado sino en la vía pública, en un espacio fácilmente accesible si nos basamos en distancias concretas, pero remotamente localizado si pensamos en ubicaciones simbólicas. El significado visual de esto sería que Mía, al ser una mujer trans y trabajadora sexual, se encuentra por fuera de la sociedad en la que se mueve: ella serviría como un resto, un sujeto con un estatuto distinto para la mayoría, al ser irrepresentable dentro del orden de cosas establecido por la comunidad (por su identidad de género, por la marginalidad e ilegalidad de su trabajo). Su irrepresentabilidad, su existencia cuestiona un sistema de verdad y por eso es un cuerpo peligroso para el orden (Foucault, 2011), para la identidad de los otros.

Además, el cuerpo trans es a su vez el cuerpo que no será buscado, el cuerpo fácilmente perdido, el cuerpo del que se mantendrá una distancia. A excepción de Makuti, su madre trans, nadie busca a Mía: ni su familia directa, ni su grupo de pares (chicas trans que desestiman la desaparición), ni la comunidad en la que vive, ni las instituciones encargadas de proteger a las personas en estos casos. Incluso en la escena siguiente, cuando aparece otra chica trans bailando música al medio de la loza deportiva, esta figura se cumple. La locación cambia: mientras Mía se encuentra en la penumbra, al medio de la carretera y de las casas, la otra mujer está al medio de 
una actividad del vecindario, es mirada por los demás, reconocida y aplaudida por el baile. Pero no está en medio de la gente, sino separada por unas rejas que rodean la cancha. Su presencia pareciera ser más tolerable por la comunidad, en tanto calza con una representación de la diversidad sexual ligada al entretenimiento o la burla (Cosme, Jaime, Merino \& Rosales, 2007), pero esto no la hace menos extraña a los ojos de los demás. Igual, las dos figuras, aluden a representaciones estereotipadas de la diversidad sexual (Hall et al., 2010), en donde las características son reducidas, simplificadas a pocos elementos claramente identificables.

Las acciones de los agresores de Mía podrían analizarse según un sistema de comprensión que garantice y brinde certezas acerca de las cosas (Foucault, 2010). En este sentido, establecen comparaciones de igualdad y desigualdad, basadas en un saber o ciencia universal, la cual podría encarnarse en la heteronormatividad de la sociedad y todas las disciplinas del saber que se encargan (en algo) de mantener esta regulación (la medicina, el derecho, la psicología, los discursos religiosos y pastorales). Estas ciencias o disciplinas han construido, en mayor o menor medida, el cuerpo trans como un signo "certero y probable" de inadecuación, ruptura del orden social, patología (característica que debería "curarse”) o peligro. Así, se ejemplifica lo sostenido por el autor "el signo empezará a significar dentro del interior del conocimiento: de él tomará su certidumbre y probabilidad” (Foucault, 2010, p.76). Esto implica que el signo no es un reflejo de la realidad, sino que la realidad construye signos que pasan por “certeros y naturales”. En el caso de las prácticas de normalización de las personas trans, estos signos estarían fundamentados en una especie de coherencia respecto a lo que debe ser un cuerpo. Dicha ausencia de coherencia podría turbar el orden cultural (Hall et al., 2010), razón por la cual aparecerían operaciones, en este caso perversas, que traten de instaurar fronteras simbólicas que permiten preservar ese orden (la humillación al cuerpo trans).

Ahora bien, las representaciones sobre el cuerpo trans implican no un único signo, sino un conjunto de signos (Foucault, 2010). El cuerpo trans que además se dedicara al trabajo sexual representaría el extremo de la abyección (por esta razón, el cuerpo de trans "bailarina" generaría una reacción distinta en la comunidad, si bien no de aceptación y cercanía, sí de cierto reconocimiento); mientras el cuerpo que mostrara signos de masculinidad heteronormativa (por ejemplo, la agresividad de los que violentan a Mía) sería la figura de lo humano. Las acciones de cada uno de estos cuerpos suponen un sistema de naturalezas complejas o clasificaciones, en la cual hay gradientes. Así, los dispositivos de control de los cuerpos trans serán más masivos y agresivos cuanto más contraria a lo heteronormativo sea su performatividad. De este análisis podemos inferir que los polos "cuerpo trans-cuerpo masculino heteronormativo" y las acciones de los sujetos producto de esta ubicación (desalentar la búsqueda de una persona trans perdida - en el caso de las chicas trans que desalientan la búsqueda de Makuti - e infligir daño y causar la muerte a un cuerpo trans) son oposiciones binarias no neutrales, lo que implica que hay una relación de poder entre ambas (Hall et al., 2010).

En el caso del cortometraje, podemos ubicar claramente dos ejes de diferenciación entre los sujetos agresores y la persona trans: la heteronormatividad versus la diversidad y el estrato socioeconómico medio/alto versus el estrato socioeconómico 
bajo. Sobre el segundo, observamos que los agresores, a pesar de no ser enfocados directamente, muestran ciertas características diferentes a la protagonista: llegan en carro y están en grupo. ¿Cómo estos dos elementos pueden dar cuenta de un estrato socioeconómico distinto? En primer lugar, el poseer un carro podría implicar un acceso económico diferenciado (recordemos que Mía se dedica al trabajo sexual, oficio marginalizado). Otro aspecto que es, a manera personal, importante es la utilización de este vehículo para encontrar a Mía. Podría plantearse que los agresores no serían residentes de zonas aledañas al lugar donde caminaba la protagonista, pues de ser así podrían haberse acercado a ella caminando o en otro medio de transporte: el uso del carro sugiere lejanía.

Finalmente, un último aspecto a analizar es la colectividad de la violencia: los agresores de Mía son un grupo de tres hombres. En el film aparecen otros grupos de personas que andan juntas: las chicas trans, compañeras de Mía. Pero es clara la diferencia entre ambos grupos. Mientras que los chicos están juntos en la misma tarea (humillar y matar a Mía), comportándose de forma coherente a su objetivo, compartiendo una identidad de la que se sienten orgullosos (no "cabros") hablando entre sí y haciendo una clara diferencia entre ellos y la otredad representada por la protagonista, el grupo de chicas trans, en la obra, se comporta de otra manera. No buscan a Mía, sino desalientan los intentos de Makuti y le dicen que "busque a su hija por su cuenta". Al parecer, no temen por su desaparición sino hasta solicitan quedarse con el cuarto de ella si es que no regresa. No hablan entre ellas, sino habla cada una por su cuenta (como en la escena del taxi). No comparten un objetivo común, sino que cada una está preocupada por su propia sobrevivencia y bienestar. La precariedad de sus existencias, en un entorno adverso y agresivo para ellas, podría explicar esta dificultad para la solidaridad de la búsqueda, aunque también podrían "relativizar" la violencia inherente a la desaparición como un mecanismo de no vincularse, de manera inconsciente, con una realidad agresiva, realidad que en algún momento podría afectarlas directamente.

Así, el poder y capacidad de acción implicarían una idea de grupo, de unidad que permite concretar acciones y comportamientos y que protege de peligros (¿Mía hubiera corrido igual suerte de haberse encontrado con solo un hombre?), mientras que el sujeto trans sería un sujeto solo, sin pertenencia arraigada al grupo. Un sujeto que solo pocos buscarían. En el film, esa persona es Makuti, quien podría encarnar otra figura periférica dentro de la periferia de lo trans: es una mujer mayor, que encarna un rol de cuidado (madre) y quien acudirá, ante la ausencia de pares, al mundo extraterrenal para buscar respuestas. Así, la figura de Makuti y la búsqueda que realiza representa una plataforma de resistencia, resistencia basada en la preocupación por el otro y en la instauración de un lazo íntimo: se reconoce a sí misma como madre de Mía. En este sentido, la desaparición de Mía, reubica a Makuti en una posición de soledad. En la última escena ella camina - de espaldas a la cámara - y se distancia del espectador, después de haber recibido la noticia: Mía ha cruzado la frontera. 


\section{BIBLIOGRAFÍA}

Butler, J (2004).

Desdiagnosticar el género. En: Deshacer el género. Nueva York: Routledge.

Butler, J (2001).

El género en disputa: el feminismo y la subversión de la identidad. México D. F.: Paidos.

Cosme, C; Jaime, M; Merino, A; Rosales, J (2007).

La imagen in/decente: Diversidad Sexual, prejuicio y discriminación en la prensa escrita peruana. Lima: Instituto de Estudios Peruanos.

Eribon, D (2001).

Reflexiones sobre la cuestión gay. Barcelona: Anagrama.

Foucault, M (2011).

Los anormales. Buenos Aires: Fondo de Cultura Económica.

Foucault, M (2010).

Las palabras y las cosas. Una arqueología de las ciencias humanas. Buenos Aires: Siglo 21, p. 39-58.

Hall, S., Restrepo, E., Walsh, C., Vich, V. (2010).

Sin garantías: Trayectorias y problemáticas en estudios culturales. Lima: Instituto de Estudios Peruanos.

Llosa, C., Posternak, F. (productores) y Llosa, C. (directora). (2012).

Loxoro [documental]. Perú: Patria Producciones. 